\title{
Gendered innovations: harnessing the creative power of sex and gender analysis to discover new ideas and develop new technologies
}

\author{
Londa Schiebinger ${ }^{1,2}$
}

Correspondence:

schiebinger@stanford.edu

${ }^{1}$ EU/US Gendered Innovations in

Science, Health \& Medicine,

Engineering, and Environment

Stanford, USA

${ }^{2}$ History of Science, Stanford

University, Building 200, Stanford,

CA 94305, USA

\begin{abstract}
'Gendered Innovations' integrate sex and gender analysis into all phases of basic and applied research to stimulate new knowledge and technologies. In so doing, Gendered Innovations enhance creativity, innovation, and gender equality. This paper reports on the interdisciplinary, international collaboration that produced: 1) 12 state-of-the-art methods of sex and gender analysis for science, health and medicine, engineering, and environmental research; and 2) and 25 case studies to illustrate how gender analysis leads to discovery. The project moves gender studies beyond identifying gender bias to prioritizing sex and gender analysis as resources to fuel new discoveries.
\end{abstract}

\section{Multilingual abstract}

Please see Additional file 1 for translations of the abstract into the five official working languages of the United Nations and Portuguese.

What happens when you bring together 60 scientists, engineers, and gender experts in a series of international, collaborative workshops? You get something radically new. That is what we did with gendered innovations. The operative question is: How can researchers harness the creative power of gender analysis to make new discoveries? Gendered Innovations integrate sex and gender analysis into all phases of basic and applied research to assure excellence and quality in outcomes (Schiebinger et al. 2011-2014). As the European Commissioner, Márie Geoghegan-Quinn put it, 'gender analysis contributes to excellence; it stimulates new knowledge and technologies; opens new niches and opportunities for research teams and results in products and services that all members of society need and demand' (Schiebinger and Klinge 2013). In other words, gendered innovations stimulate creativity, innovation, and gender equality.

Over the past 40 years, gender studies have developed primarily in the humanities and social sciences - and have gone far toward remaking those disciplines. Broadly speaking, this scholarship has had taken three analytical approaches to issues of science and technology:

1. 'Fix the Numbers of Women' focuses on increasing women's participation. 
2. 'Fix the Institutions' promotes gender equality in careers through structural change in research organizations.

3. 'Fix the Knowledge' or 'gendered innovations' stimulate excellence in science and technology by integrating gender-based analysis into research.

This article focuses on this third approach, 'Fix the Knowledge' or 'gendered innovations.' While it is useful to distinguish these three approaches for analytical purposes, they are deeply interrelated. Efforts to increase women's participation will not succeed without mainstreaming the methods of sex and gender analysis into knowledge production; integrating gender analysis into research will not succeed without a full complement of women and men.

Gender theory has done much to transform the humanities and social sciences, yet it has had little success in the natural sciences and engineering. Efforts to 'fix the knowledge' in science and technology began with new developments in feminist theory in the 1980s. Major epistemologists, such as Evelyn Fox Keller, Donna Haraway, and Sandra Harding, began challenging the idea that scientific knowledge is objective. Keller applied object/relations theory to reveal how science is 'masculinist'; her goal was to reclaim science as a human as opposed to a 'masculine' project and to rethink Western divisions of intellectual and emotional labor (Keller 1985).

Science theorists called for better understandings of the social contexts generating science - for example, Haraway's 'situated knowledge' (Haraway 1988) and Harding's 'strong objectivity' (Harding 1991). Both Haraway and Harding argue that what natural scientists call 'objectivity' is weak because researchers shy away from analyzing the politics of knowledge; that is, they fail to understand how research priorities are set and who benefits (and who does not) from a particular line of research.

Standpoint theory of the 1990s was also central to efforts to remake science. Importantly, standpoint theory argued for new starting points for scientific research: marginal lives - those of women, people of color, gays, lesbians, transgender persons, and others lacking social and economic privilege. Standpoint theory interacted strongly with postmodernism to call into question the singular category 'woman' that ignores powerful intersections of gender, race, and class (Harding 2004).

\section{Fixing the knowledge: methods of sex and gender analysis}

The slow uptake of gender analysis in the natural sciences and engineering is the problem that the Gendered Innovations project set out to solve. Gendered Innovations began at Stanford University in 2005 with a major conference. Policy advances in Europe (see below) brought European Commission support for the project in January 2011. The U.S. National Science Foundation joined the project in January 2012. The project has consisted of an international, interdisciplinary collaboration of over 60 experts from across Europe, the United States, and Canada. The Republic of Korea and the Republic of China have recently joined the effort.

Historically, feminists have critiqued science and technology after the fact. A rich and important literature has critiqued science and technology from multiple gender points of view (reviewed in Schiebinger 2014). Gender experts are now turning critique toward a positive research program that - from the beginning - integrates gender analysis 
into basic and applied research. Based on 40 years of gender studies of science and technology, Gendered Innovations have developed practical methods of sex and gender analysis specifically for science and engineering in collaboration with scientists and engineers (see Table 1) (Schiebinger et al. 2011-2014). State-of-the-art methods of sex and gender analysis work alongside other methodologies in a particular field to provide yet further 'controls' (or filters for bias), enhancing excellence in science, medicine, and engineering research, policy, and practice. The methods of sex and gender analysis are one set of methods among many that researchers will bring to a project. As with any set of methods, new ones will be fashioned and others discarded as circumstances change. The value of their implementation depends on the creativity of the research team. Some of these methods plus their practical application in case studies are summarized in this article.

This article treats integrating sex and gender into research. Sex refers to biological qualities or classifications of sexually reproducing organisms, generally female, male, and/or intersex. Gender refers to cultural and social attitudes, norms, and ideologies that together shape and sanction 'feminine' and 'masculine' behaviors, products, technologies, environments, and knowledges. 'Femininities' and 'masculininities' describe behaviors on a continuum of diverse gender identities and behaviors that change with historical era, culture, and place, such as the 1950s versus the 2010s, Spain versus Germany, and urban versus rural areas. Gender also differs by specific social contexts, such as at work versus at home. Gender identities interact with other identities, such as ethnicity or class. Gender does not necessarily map onto sex.

Important to this project is to understand how sex and gender should be considered in each step of the research process from strategic considerations for establishing priorities and theory to more routine tasks of formulating questions, designing methodologies, and interpreting data. Each of the 12 methods listed in Table 1 help scientists, engineers, designers, etc. pose questions, for example, when setting research priorities or developing basic conceptual frameworks for a project in order to integrate sex or gender considerations into that step of the research process. The organization of the materials below follows this scheme. Evidence shows that integrating sex and gender analysis into basic and applied research enhances excellence in science, health and

Table 1 Methods of sex and gender analysis

\begin{tabular}{ll}
\hline & Methods \\
\hline 1. & Rethinking research priorities and outcomes \\
3. & Rethinking concepts and theories \\
4. & Formulating research questions \\
5. & Analyzing sex \\
6. & Analyzing gender \\
7. & Analyzing how sex and gender interact \\
8. & Enalyzing factors intersecting with sex and gender \\
9. & Designing health and biomedical research \\
10. & Rethinking standards and reference models \\
11. & Rethinking language and visual representations \\
12. &
\end{tabular}


medicine, and engineering (Klinge 2008; Schiebinger 2008; Wajcman 2007; Faulkner 2001; Bührer and Schraudner 2006; Schraudner 2010).

\section{Methods and case studies}

Through a series of collaborative, international workshops, Gendered Innovations developed: 1) practical methods of sex and gender analysis for scientists and engineers (as discussed above), and 2) 25 case studies illustrating in concrete ways how sex and gender analysis leads to innovation in science and technology. This section summarizes some of these methods and case studies. These materials are drawn from the Gendered Innovations website - and there readers can find the full methods and case study plus all citations to original research and a list of contributors who assisted in developing these materials (Schiebinger et al. 2011-2014). Each short example here highlights a problem, a method of sex or gender analysis, and solutions or gendered innovations.

\section{Method 1: rethinking research priorities and outcomes Case study: HIV microbicides}

The first method poses questions to researchers to assist them in considering sex or gender when setting research priorities and outcomes. Governments, industries, funding agencies, and scientists themselves set priorities for future research. Research priorities respond to numerous social imperatives and background assumptions, such as intended markets, funding levels, lobbies, and notions about gender. Questions related to gender include: How do gender norms, behaviors, and attitudes influence research priorities? Do established practices and priorities of funding agencies enforce gender bias or encourage gender equality and innovation?

Every research project begins by setting priorities, that is, choosing how to invest limited social and intellectual resources and what questions to pursue. Discussing research priorities and outcomes is complex; here, space allows for one example from the case study 'HIV microbicides'.

Over the past few years, Andrew Szeri, Professor of Mechanical Engineering and Dean of the Graduate Division at the University of California, Berkeley, set out to shift research priorities in his lab from applied physics to biomedical engineering. As Szeri explains, 'the mathematical methods (on which I rely heavily) haven't changed much at all. It is, rather, the goals of the projects which have. The goals of the research changed from understanding the physics of a problem to developing models that could be used to evaluate devices or treatments for medical conditions' (Szeri 2009).

This shift in research priorities led to two gendered innovations: The first has to do with participation (Who does science?), and the second has to do with outcomes (What science is done?). First, Szeri's shift dramatically increased the number of women in his lab. Engineering is a field where - despite national and international efforts - women remain underrepresented. While many schemes exist to increase women's participation, few have considered how project priorities and objectives impact women's and men's proportional participation in research (Rosser 2008; Marchetti and Raudma 2010). This case study suggests that increasing the number of women in engineering requires more than programs focused on removing subtle gender bias from hiring and promotion practices, stopping tenure clocks, leadership training, and the like; such interventions are necessary but not sufficient. Increasing the numbers of women may also require 
'fixing the knowledge', or reconceptualizing research to include methods of sex and gender analysis in creative and forward-looking ways (Schiebinger and Schraudner 2011). Szeri's new research priorities enhanced gender equality in his lab.

Second, changing research priorities also expanded research in the field of fluid mechanics, Szeri's area of expertise. Although the research conducted in Szeri's lab has many applications, one project focused on developing woman-controlled HIV microbicide delivery. About 33 million people are infected with HIV worldwide; some $72 \%$ of HIV-related deaths occur in sub-Saharan Africa, where the prevalence of HIV infection is six times higher than the world average. HIV flourishes in regions where women's subordinate status makes it difficult to negotiate safe sex (UNAIDS 2010). Currently, female condoms are the only woman-controlled HIV prevention option, but they are detectable and may require partner consent. They are also less available and more expensive than male condoms (Mack et al. 2010).

Szeri and his co-workers sought to assist women protect themselves from AIDS, especially in cultures where they cannot say 'no' to sex or cannot rely on their partners to use condoms. Specifically, Szeri's lab developed a vaginal gel to deliver microbicides. The physics of the problem is complex: the gel needs to coat the vagina completely and not fall out with the pull of gravity (Szeri et al. 2008). These gels can also deliver birth control, if desired. Resetting research priorities thus led to a gendered innovation - a new product to help women protect themselves from AIDS.

\section{Method 2: rethinking concepts and theories \\ Case study: genetics of sex determination}

Theories provide frameworks for explaining and predicting phenomena; concepts relate to how data are described and interpreted, including how particular phenomena are categorized. Theories and concepts frame how research is conducted within a particular field or topic area, influencing: what constitutes an interesting research topic, what requires explanation, what counts as evidence, how evidence is interpreted, and what methods are considered appropriate. The case study 'genetics of sex determination' provides an example of how questioning a basic concept from a gender perspective - in this case, the notion of the female developmental pathway as a 'default' - opened new areas to research.

Until about 2010, research on sex determination (the differentiation of the embryonic bipotential gonad into a testis or an ovary) focused primarily on testis development (Uhlenhaut et al. 2009; Richardson 2013). Andrew Sinclair's 1990 Nature paper famously identified a Y-chromosome gene as the sex-determining region Y (SRY). SRY and its downstream targets, such as SOX9, became the focus of research. Female sexual development, by contrast, was thought to proceed by 'default' in the absence of SRY.

Default means failure to act; neglect or a preselected option adopted when no alternative is specified. In the case of sex determination, 'default' became the prevailing concept framing research into female pathways - i.e., it was assumed that an ovary results in the absence of other action. In the case of the genetics of sex determination, biologists failed to question the 'default' model for ovarian development inherited from the 1950s and 1960s. The notion of a 'passive' female fit with current scientific theories and 
gender assumptions in the broader society. The active processes controlling ovarian development remained unexplored.

Rethinking foundational concepts, questioning the notion of 'default', led to new questions about ovarian development and the discovery of a cohort of genes required for ovarian function (see Figure 1). Gender analysis led to three innovations in this field:

1. Recognition of ovarian determination as an active process (Veitia 2010). These investigations have also enhanced knowledge about testis development and how the ovarian and testicular pathways interact.

2. Discovery of ongoing ovarian and testis maintenance. Research into the ovarian pathway revealed that the transcriptional regulator FOXL2 must be expressed in adult ovarian follicles to prevent 'transdifferentiation of an adult ovary to a testis' (Uhlenhaut et al. 2009). Subsequently, researchers found that the transcription factor DMRT1 is needed to prevent reprogramming of testicular Sertoli cells into granulosa cells (Matson et al. 2011).

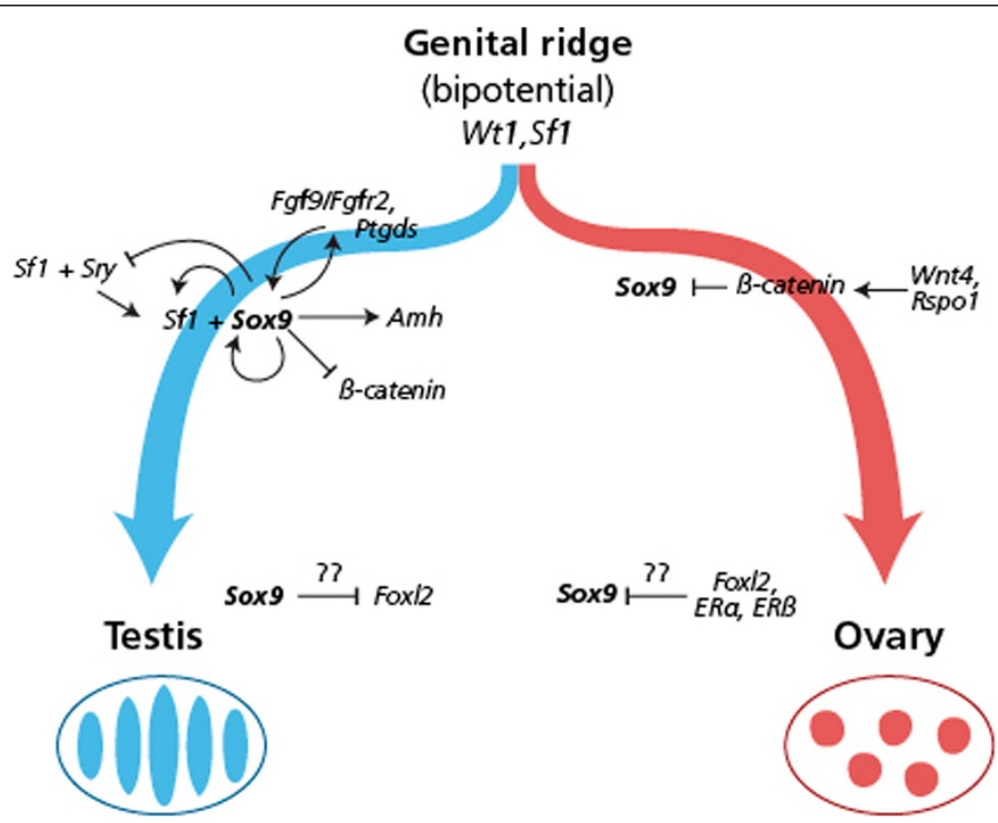

Figure 1 Molecular and genetic events in mammalian sex determination. Genes in the female pathway repress Sox9; genes in the male pathway express it. "The bipotential genital ridge is established by genes including $W t 1$ and Sf1, the early expression of which might also initiate that of Sox9 in both sexes. $\beta$-catenin can begin to accumulate as a response to Rspo1-Wrt4 signaling at this stage. In XX supporting cell precursors, $\beta$-catenin levels could accumulate sufficiently to repress SOX9 activity, either through direct protein interactions leading to mutual destruction, as seen during cartilage development, or by a direct effect on Sox 9 transcription. However, in XY supporting cell precursors, increasing levels of SF1 activate Sry expression and then SRY, together with SF1, boots Sox9 expression. Once SOX9 levels reach a critical threshold, several positive regulatory loops are initiated, including autoregulation of its own expression and formation of feed-forward loops via FGF9 or PGD2 signaling. If SRY activity is weak, low or late, it fails to boost Sox9 expression before $\beta$-catenin levels accumulate sufficiently to shut it down. At later stages, FOXL2 increases, which might help, perhaps in concert with ERs, to maintain granulosa (follicle) cell differentiation by repressing Sox9 expression. In the testis, SOX9 promotes the testis pathway, including Amh activation, and it also probably represses ovarian genes, including Wnt4 and FoxI2. However, any mechanism that increases Sox9 expression sufficiently will trigger Sertoli cell development, even in the absence of SRY" (Sekido et al. 2009). 
3. New language to describe gonadal differentiation. Researchers have dismissed the concept of 'default' and emphasize instead that, while female and male developmental pathways are divergent, the construction of an ovary (like the construction of a testis or any other organ) is an active process. Each pathway requires complex cascades of gene products in proper dosages and at precise times.

\section{Method 3: formulating research question}

\section{Case study: heart disease in women}

Research questions typically flow from priorities and from the theories and concepts that frame research (see above). Research priorities - along with concepts and theories - function to: 1) delimit questions asked - and, by implication, questions not asked, and 2) frame research design and choice of methods. The choice of questions asked is often underpinned by assumptions - both implicit and explicit - about sex and gender. Formulating new research questions constitutes method 3.

Heart disease research in women offers one of the most developed examples of gendered innovations. Although heart disease is a major killer of women in developed countries, it has been defined primarily as a male disease, and 'evidence-based' clinical standards have been created based on male pathophysiology and outcomes. As a result, women are often mis- and under-diagnosed (Oertelt-Prigione and Regitz-Zagrosek 2012).

Improving women's healthcare has required new social, medical, and political judgments about women's social worth, and a new willingness to support women's health and wellbeing. Analyzing sex and gender in heart disease has also required formulating new research questions about disease definitions, symptoms, diagnosis, prevention strategies, and treatments. Once sex and gender were factored into the equation, knowledge about heart disease increased dramatically. As is often the case, including women subjects - of diverse social and ethnic backgrounds - in research has led to a better understanding of disease.

To take just one example, consider how underlying pathophysiology may differ between women and men (Bairey Merz et al. 2010). Coronary angiography, the 'gold standard' for diagnosing patients with chest pain, typically results in a diagnosis of obstructive coronary artery disease $(\mathrm{CAD})$ in men (see Figure 2 right), but frequently fails to identify the cause in a large proportion of women (Bugiardini and Bairey Merz 2005). As a result, many

Diffuse atherosclerosis Most often seen in younger women with IHD
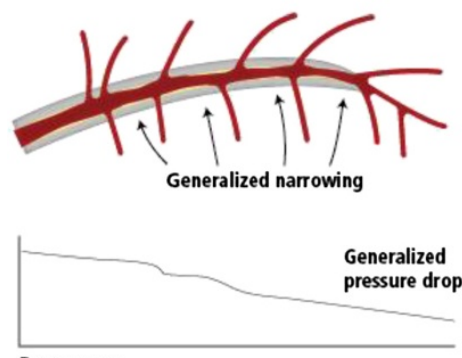

Presssure

\section{Obstructive atherosclerosis Most often seen in men and} older women

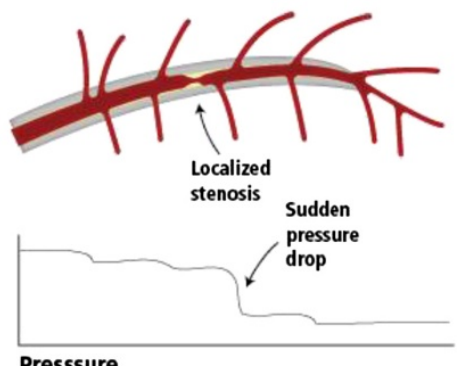

Figure 2 Coronary angiograms for patients with chest pain. Women are more likely to have minor or no obstruction. Adapted with permission from (K. Lance Gould 1999). 
women with chest pain, but 'normal' angiograms (see Figure 2, left), may be told that they have no significant disease and sent home.

New studies show, however, that the prognosis for these women is not benign: Women with a primary diagnosis of 'non-specific chest pain' may suffer heart attack or stroke shortly after being discharged from hospitals (Robinson et al. 2008). This may also be true for some men. Large-scale randomized trials are needed to better understand the pathophysiology and optimal therapies for women and men with angina and 'normal' angiograms.

After 20 years of research, sex and gender analysis has prompted policy changes, increased the representation of women subjects in heart disease research, and enhanced knowledge about diagnosis and treatment in women and men alike. In addition, robust prevention campaigns have utilized understandings of gender to promote heart-healthy behaviors, such as exercise and tobacco smoking cessation.

\section{Method 4: analyzing sex}

\section{Case study: stem cells}

Sex (referring to biological qualities, as discussed above) is an important variable to consider when setting research priorities, developing hypotheses, and formulating study designs. In biomedical research, sex may need to be analyzed in humans, animals, organs, tissues, cells, and their components (Institute of Medicine 2012; Wizemann and Pardue 2001). In engineering, sex may need to be analyzed at the levels of user physiology and biomechanics in both product and systems design.

Analyzing sex involves at least five steps: 1) reporting the sex of research subjects or users; 2) recognizing differences that exist between but also within groups of females and males, and identifying potential overlap between groups (Figure 3);3) collecting and reporting data on factors intersecting with sex in study subjects or users/consumers, such as age, socioeconomic status, and ethnicity; 4) analyzing and reporting results by sex; and 5) reporting null findings. This final step is important: Researchers should report when sex differences (main or interaction effects) are not detected in their analyses to reduce publication bias and improve meta-analyses.

Method 4, analyzing sex, is basic and commonly used in gendered innovations case studies, including animal research, environmental chemicals, nutrigenomics, and pregnant crash test dummies. Here, we take an example from stem cell research. Stem cell

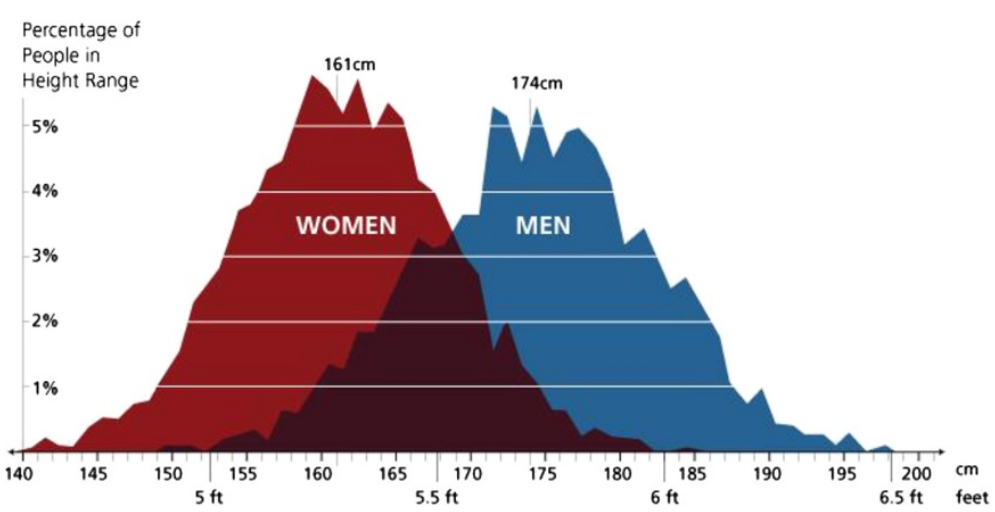

Figure 3 Height of adult women and men. Within-group variation and between-group overlap are significant. Data from U.S. CDC, adults ages 18-86 in 2007. 


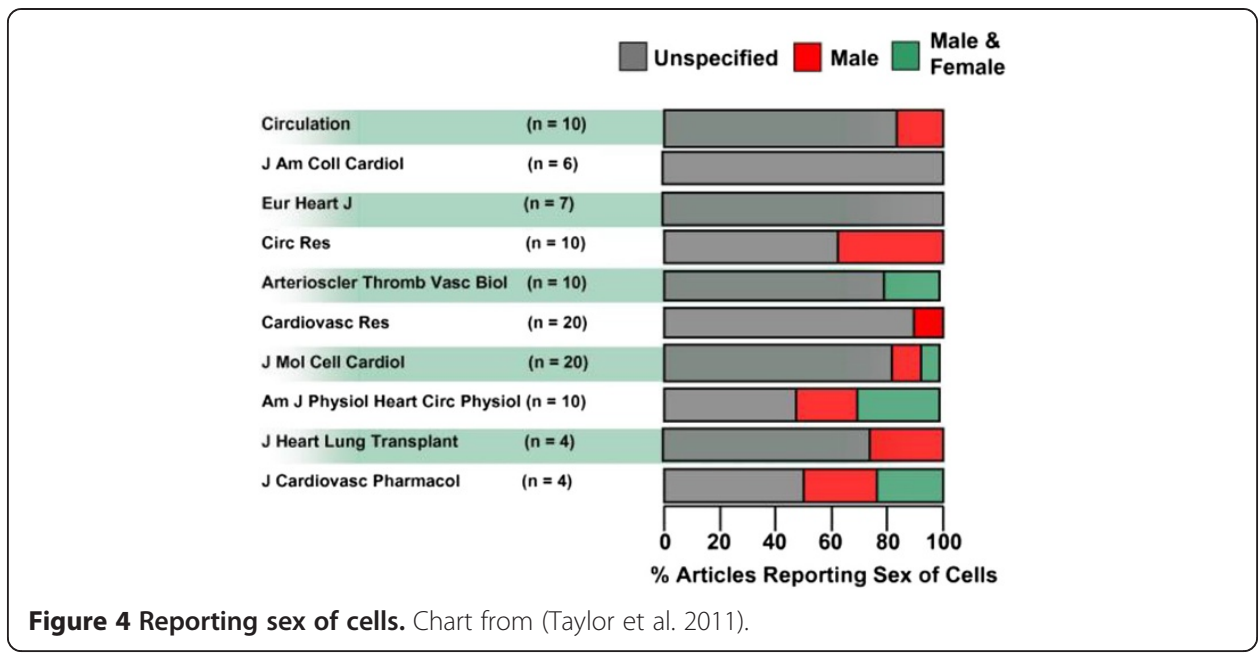

therapies hold great promise for treatments for debilitating diseases, such as Parkinson's disease and muscular dystrophy, although few are currently in use.

Oddly enough, still today most research is done in males (Beery and Zucker 2011). A 2011 Mayo Clinic study showed that for the most part, the sex of the cell is not reported (Taylor et al. 2011 - see Figure 4). This is money wasted, research that is lost to future meta-analysis.

Not taking the sex of the cell into account can lead to life-threatening consequences and leave researchers with unsolved puzzles. For example, an international collaboration between labs in Norway and Australia encountered problems working with bone marrow stem cells in mice. Researchers in the labs appropriately used both male and female mice (excellent research design), but they used all female stem cells without considering why. This was an unconscious decision that does not reflect best scientific practice. The result was that their male mice died - and they did not understand why.

Taking sex into account will be important to advancing basic knowledge. Research has documented potential sex differences in the therapeutic capacity of stem cells. Musclederived stem cells, for example, show variability in proliferation and differentiation. Researchers found that XX cells showed a higher regenerative capacity than XY cells. This may constitute an important clinical finding but requires further investigation. Researchers should consider all combinations of donor/recipient sex interaction before ruling out sex as a variable (see Figure 5). This type of donor/recipient analysis has also been important in human organ transplant (Kaczmarek et al. 2013).

The effects of sex, however, may also vary by type of stem cell used, type of disease treated, and hormonal and environmental factors, plus their intersections. It is complicated, but research that takes these factors into account leads to better outcomes.

\section{Method 5: analyzing gender}

\section{Case study: machine translation}

While many of the Gendered Innovations methods integrate gender, this method focuses specifically on analyzing gender, a major tool for identifying unconscious bias. Gender is a primary linguistic, cognitive, and analytical category in science, health and medicine, and engineering. Yet gender assumptions often go unquestioned and hence 


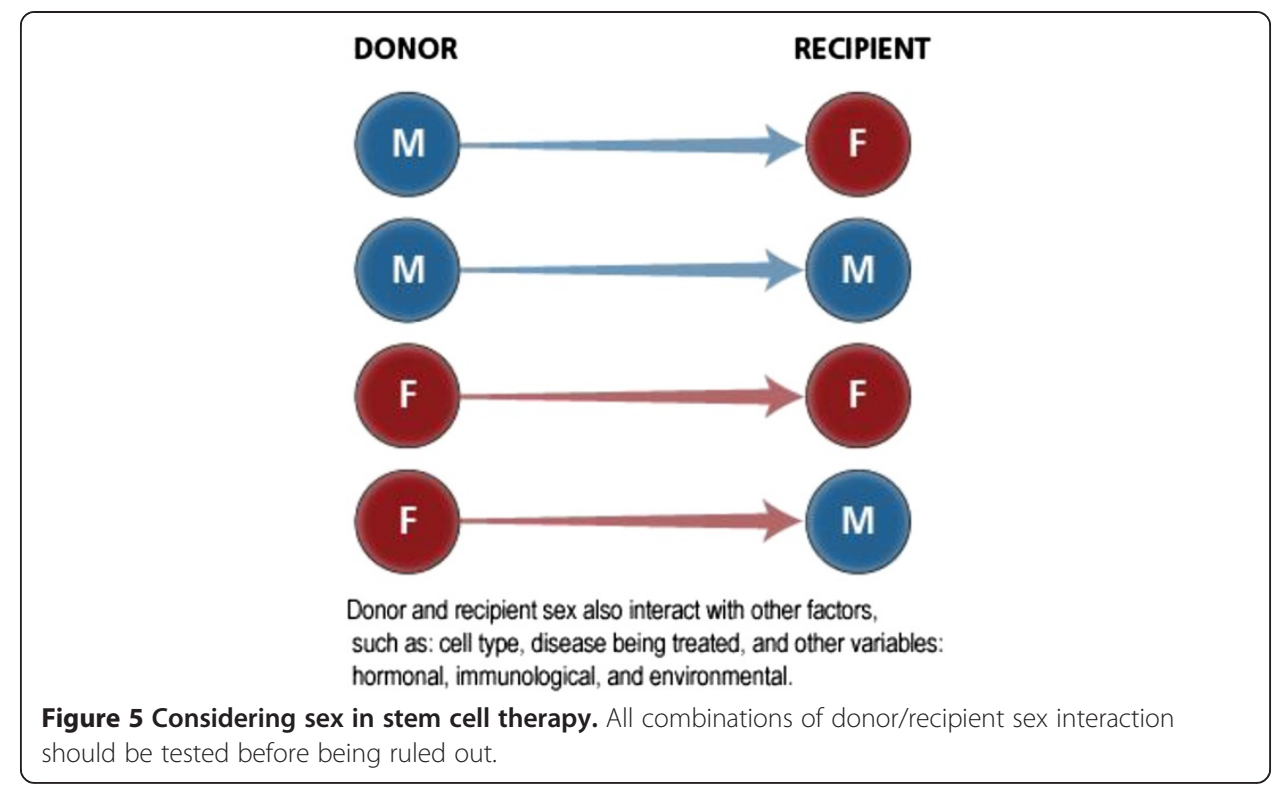

remain invisible to scientific communities. These background assumptions unconsciously influence scientific priorities, research questions, and choices of methods. Gender comes into play when cultural attitudes shape and are shaped by: 1) researchers' gender assumptions and behaviors as these relate to the proposed research; 2) research subjects' and users' gender needs, assumptions, and behaviors as these relate to the proposed research; and 3) the interaction of numbers 1 and 2.

When gender assumptions remain unexamined, they may introduce bias into science and engineering. Take for example Google Translate. Machine translation becomes increasingly important in a global world. In March 2011, I was in Madrid and interviewed by some Spanish newspapers. When I returned home, I zoomed the articles through Google Translate and was shocked that I was referred to repeatedly as 'he'. Londa Schiebinger, 'he says', 'he wrote', or occasionally, 'it says'. State-of-the-art translation systems, Google Translate, and its European equivalent, SYSTRAN, have a male default.

How can such a cool company as Google make such a fundamental error? Google Translate defaults to the masculine pronoun because 'he said' is more commonly found on the web than 'she said.' We know from NGram (another Google product) that the

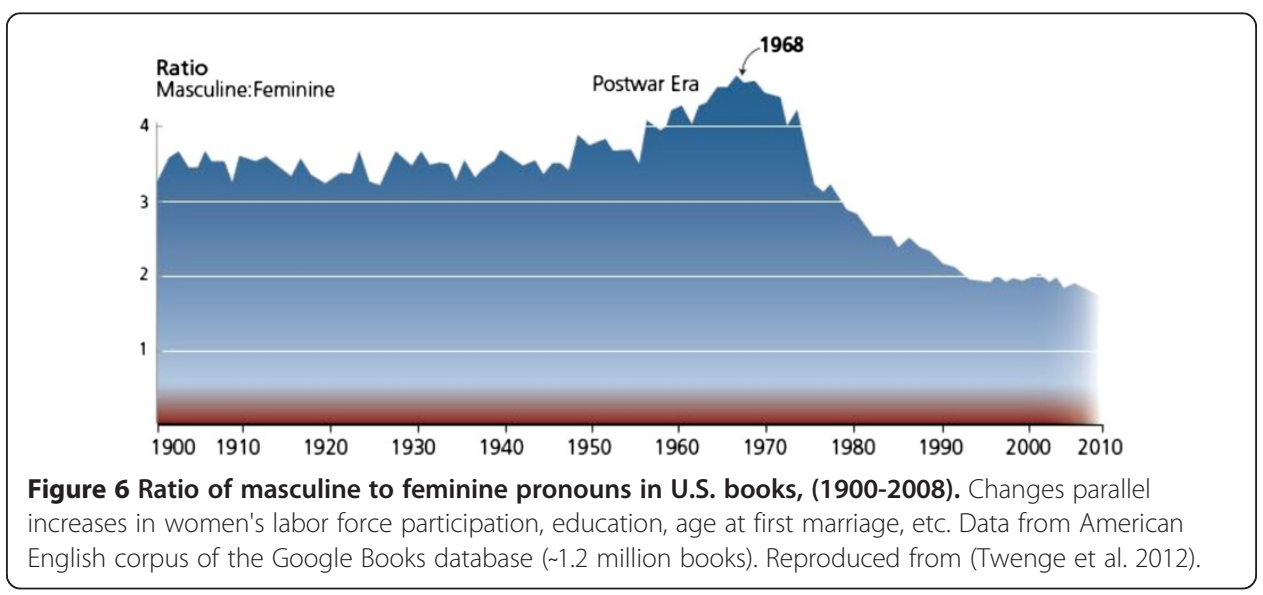


ratio of masculine to feminine pronouns has fallen dramatically from a peak of 4:1 in the 1960s to 2:1 since 2000 (Twenge et al. 2012) (Figure 6). This parallels exactly the women's movement and robust governmental funding to increase the numbers of women in science. With one algorithm, Google wiped out 40 years of revolution in language - and they did not mean to. This is unconscious gender bias.

The fix? We brought this problem to a Gendered Innovations workshop and invited top researchers from Google and Stanford. They listened for about $20 \mathrm{~min}$ - they got it. And they said, 'we can fix that!' Analyzing gender - and its cultural defaults - has led to new research priorities in this area.

A deeper fix to this problem would be to integrate gender analysis into the engineering curriculum so that engineers do not make such errors in the future. RWTH Aachen University, Germany, implemented a course on Gender and Diversity in its School of Engineering in 2013.

\section{Method 6: analyzing how sex and gender interact}

\section{Case study: assistive technologies for the elderly}

'Sex' and 'gender' are distinguished for analytical purposes. In reality, sex and gender interact (mutually shape one another) to form individual bodies, cognitive abilities, and disease patterns, for example. Sex and gender also interact to shape the ways engineers design objects, buildings, cities, and infrastructures. And, sex and gender intersect in important ways with a variety of other social factors, including age, educational background, socioeconomic status, ethnicity, geographical location, etc.

Figure 7 suggests how sex and gender interact to create individual behaviors, health outcomes, and attitudes, etc. across the life span. Although women and men are fundamentally alike, sex and gender can work together to produce differing outcomes.

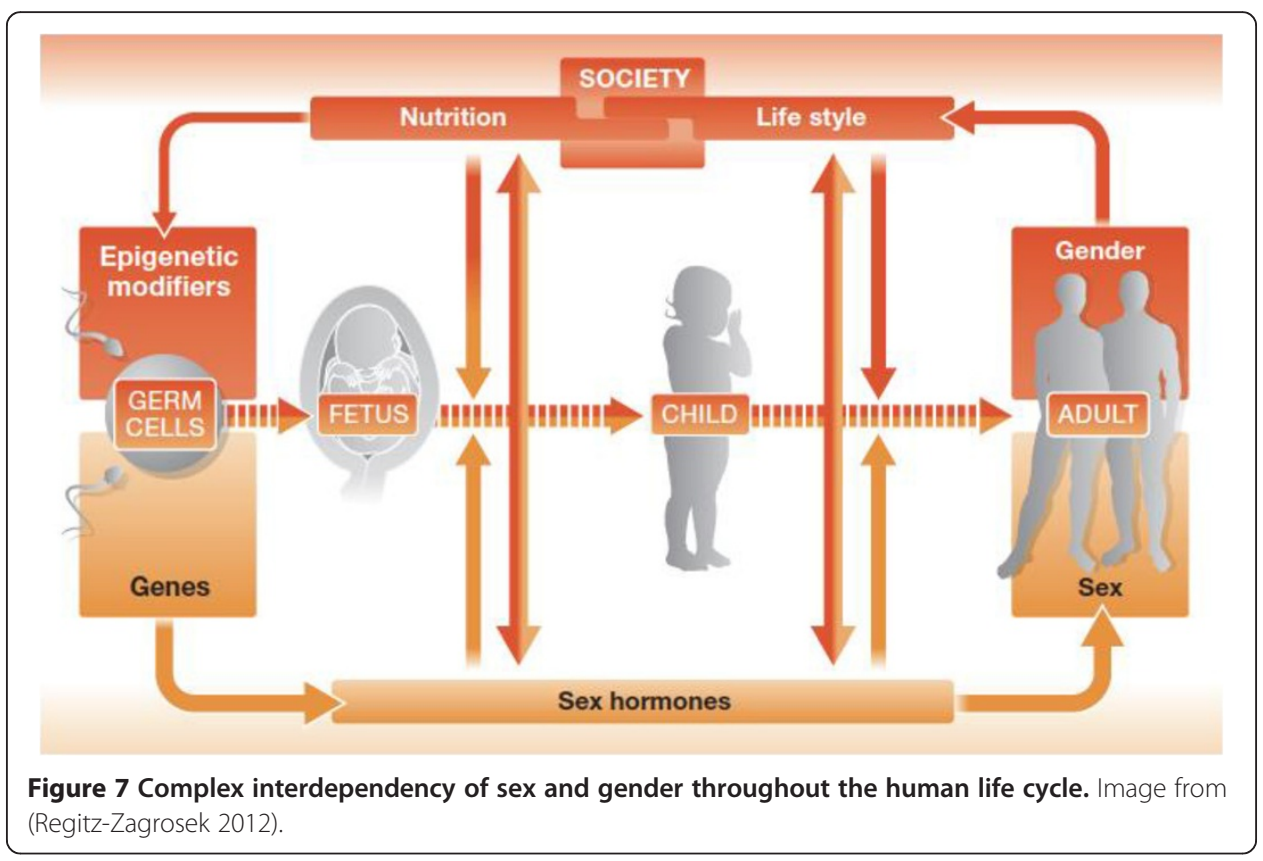


Take the example of assistive technologies for the elderly. The world population will age dramatically by 2050. Large elderly populations will place a growing strain on human caregivers, health, and social systems. This case study looks at the 'value added' of considering both sex and gender when designing assistive technologies.

Assistive technologies support independent living for the elderly. When developing these technologies, it is important to look at sex differences. Women, for example, tend to live longer but may have more debilitating diseases than men; men, for example, may lose their hearing early. In addition, it is also important to look at gender differences: As they age, women and men have different partnering patterns (elderly women more often live alone), men and women have different experience in household management, and elderly men and women have different receptivity to technology. Researchers who analyze how sex and gender interact in individual women and men will design the most effective and marketable products (Figure 8).

Gender issues become particularly important as assistive technologies become more personalized. Engineers in the U.S., Europe, and Japan are developing robots for elderly people. Georgia Tech, for example, has created a robotic nurse, named 'Cody' that can bathe elderly people. Bathing is an intimate relationship that requires careful thought - for women and for men. Carnegie Mellon is developing HERB (Home Exploring Robot Butler) that can fetch household items for you, remind you to take your medicine, or even clean up the kitchen.

As these robots enter our lives, we humans will gender them. Studies of machine voices - synthetic or machine-generated voices - show that human listeners assign gender to machine voices; that is to say, we interpret these machine-generated voices as the voice of a woman or a man, even when designers have tried to create a gender-neutral voice (Nass and Brave 2005; Lee et al. 2007). As soon as humans interpret a voice as masculine or feminine, we tend to overlay our cultural stereotypes onto the machine. Critically considering sex and gender when designing new assistive technologies will be one important factor to ensure that products embody non-stereotypical and forwarding-looking notions of gender.

\section{Method 7: analyzing factors intersecting with sex and gender \\ Case study: osteoporosis research in men}

While it is important to analyze sex and gender, and how they interact, other factors also intersect with sex and gender. These factors can be biological, socio-cultural, or psychological and may include genetics, age, sex hormones, reproductive status, body composition, comorbidities, body size, disabilities, ethnicity, nationality, geographic location, socioeconomic status, educational background, sexual orientation, religion, lifestyle, language, family configuration, environment, etc.

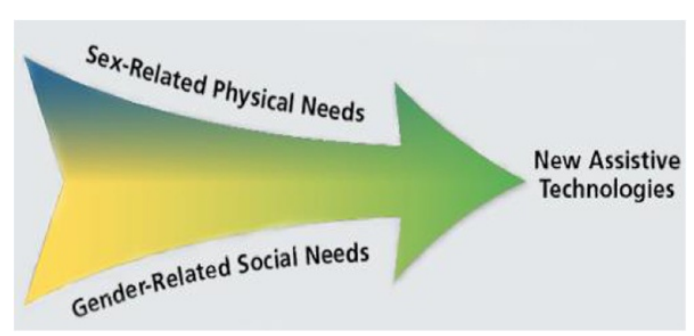

Figure 8 New assistive technologies. 
This method applies to nearly every research project - and it is often a game changer. Intersecting factors, such as ethnicity or socioeconomic background, may reveal subgroup differences among women and among men that would be obscured by analyzing only gender or only sex. Researchers can investigate how sex and/or gender intersect with other significant factors by: 1) identifying all relevant factors, 2) defining those factors, and 3) identifying intersections between those variables.

Several examples above looked at problems that arise when the male is taken as the norm (as in the case of the genetics of sex determination, heart disease, or machine translation). The case study 'osteoporosis research in men' reveals that assuming a female norm can be detrimental to men.

Employing method 2, rethinking concepts and theories, we see that osteoporosis has long been defined as a disease primarily of post-menopausal women - an assumption that has shaped its screening, diagnosis, and treatment. Why is this a problem? It is true that women suffer more from osteoporosis than men and at an earlier age. Men over age 75, however, account for a third of hip fractures - and when men break their hips, they die more often than women (Burge et al. 2007). Basic concepts in osteoporosis research need to be reconsidered.

Despite the relatively high numbers of men who suffer from osteoporosis, the basic diagnostics for the disease were developed using young, white women (aged 20 to 29 years - CDC 2002). The gendered innovation in this particular case study came in 1997 when a reference population of young men was established to diagnosis osteoporosis in men. Although reference populations for men have been developed, disease in men is still identified using the female diagnostic cutoff. It remains unclear whether this cutoff applies to men or not (Szulc et al. 2012).

The discerning reader will have zeroed in on the fact that reference populations discussed above are white. Method 7, analyzing factors intersecting with sex and gender, pushes researchers to go beyond looking only at sex and gender to consider differences among men with different lifestyles. Bones respond to biological preconditions and also to lifestyle (diet, smoking, exercise - Fausto-Sterling 2005; Fausto-Sterling 2008). Lifestyles can differ dramatically across cultures, ethnicities, and socioeconomic class. Current studies are analyzing cohorts of men from China and Sweden, for example, to understand these types of differences. The goal is to maintain healthy bones in diverse populations.

\section{Policy recommendations and conclusions}

Policy is one driver of innovation and can help encourage scientists and engineers integrate sex and gender analysis into their research (Johnson et al. 2014). Interlocking policies need to address gate keepers, i.e., granting agencies, hiring committees, editors of peer-reviewed journals, industry leaders, and educators.

1. Granting agencies can ask applicants to explain how sex and gender analysis is relevant their proposed research.

a. The European Commission has set the standard for policies in this area. Since 2003, the European Commission has supported 'questioning systematically 
whether, and in what sense, sex and gender are relevant in the objectives and in the methodology of projects' (European Commission 2003). To better meet its grand societal challenges, the Commission has been reaffirmed and expanded these policies in Horizon 2020, its current funding framework. The Commission states, 'Integrating gender/sex analysis in research and innovation (R\&I) content helps improve the scientific quality and societal relevance of the produced knowledge, technology and/or innovation.' In the proposal template, under 'concept and approach', applicants are asked 'Where relevant, describe how sex and/or gender analysis is taken into account in the project's content' (European Commission 2011; 2013; 2014). The Commission identified some 130 fields of science and technology that gender analysis could benefit, including computer hardware and architecture, biodiversity, ecology, biophysics, oceanography, geosciences, organic chemistry, aeronautics, space medicine, and nanotechnology. Further, the Commission supports gender training as an eligible cost.

b. Since 1993, the U.S. National Institutes of Health (NIH) has required grantees to include women and minorities in phase III clinical trials. Beginning October 2014, the NIH will mandate that applicants 'report their plans for the balance of male and female cells and animals in preclinical studies', unless sex-specific inclusion is unwarranted, based on rigorously defined exceptions (Clayton and Collins 2014).

c. Since 2010, all 13 Canadian Institutes of Health Research (CIHR) have required applicants to consider gender in their research. CIHR states that 'the purpose of this tool is to give health researchers a framework for thinking through how gender and/or sex might be integrated into their research designs' (CIHR 2012).

d. The Bill \& Melinda Gates Foundation has required applicants to consider gender in agricultural research since 2008 and reaffirmed this requirement in 2013 (Gates Foundation 2008, 2013). Foundation program officers also offer assistance in incorporating gender analysis into research.

e. A number of national research councils, such as the Irish Research Council (2013a, b) and the Research Council of Norway (2014) also ask applicants to consider the gender-based analysis and impacts in the research proposal.

f. The Republic of Korea has founded the Advanced Institute of Women in Science, Engineering and Technology (WISET) supported by the Ministry of Science, Education, and Technology, and since 2013 has a Gendered Innovations research group focused on integrating gender-based analysis into research.

g. Taiwan has founded an 'Infuse Gender Analysis into Science and Research' group. The National Science Council of Taiwan also supported the International Conference on Women in Science and Technology in 2013 that networked gender researchers across Asia.

2. Editorial boards of peer-reviewed journals can require sophisticated gender-based analysis when selecting papers for publication. A number of journals have implemented this policy. Clinical Orthopaedic and Related Research has recommended that studies be sufficiently powered to analyze gender (Leopold et al. 2014 - see Table 2). In 2012, each of the American Physiological Society's 14 journals required that authors report and analyze sex (Miller 2012). The European Association of Science Editors expects to launch a set of standard policies for reporting gender in S\&T journals in June 2014. 
Table 2 Clinical Orthopaedic and Related Research recommendations for authors:

\begin{tabular}{l}
\hline Recommendations \\
\hline (orign studies that are sufficiently powered to answer research questions both for males and females \\
2. Provide sex- and/or gender-specific data where relevant in all clinical, basic science, and \\
epidemiological studies. \\
Analyze the influence (or association) of sex or gender on the results of the study, or indicate in the \\
Patients and Methods section why such analyses were not performed, and consider this topic as a \\
limitation to cover in the Discussion section. Readers need to know whether the results generalize \\
to both sexes/genders. \\
Indicate (if sex or gender analyses were performed post-hoc) that these analyses should be interpreted \\
cautiously because they may be underpowered (leading to a false conclusion of no difference). If there \\
are many such analyses, indicate that they may lead to spurious significance and an erroneous \\
conclusion of a sex- or gender-related difference.
\end{tabular}

3. Universities should integrate the results of gendered innovations into their curricula. In both medicine and engineering, teaching new materials that incorporate sex and gender can be a matter of life or death. If physicians do not know how to treat osteoporosis in men or engineers do not take smaller, lighter drivers into account, tragic accidents can happen. To remedy this, universities must train the next generation in sex and gender analysis. As discussed above, RWTH Aachen University, Germany, has implemented such reforms. Sweden's Karolinska Institute and Germany's Charité Universitätsmedizin have both created centers for gender medicine that promote sex and gender analysis research and medical education (Haafkens and Klinge 2007). The next step is to reform the curriculum to incorporate sex and gender.

4. University hiring and promotion committees can evaluate researchers and educators on their success in implementing gendered innovations. This can be one factor taken into consideration.

5. Industry can promote products, and systems that incorporate the smartest aspects of gender can open new markets (Sørensen et al. 2012: GI Checklist). Products that meet the needs of complex and diverse user groups enhance global competitiveness and sustainability.

Gendered Innovations have moved gender studies beyond identifying gender bias to prioritizing gender analysis as a resource to create new knowledge and technology. The key step is - from the beginning - to incorporate sex and gender analysis into each step of the research process. This move from reactive to proactive means that researchers have a better chance of getting it right the first time. Discoveries, pharmaceuticals, technologies, and the like will no longer need to be retrofit to the neglected sex. Incorporating sex and gender as robust variables into research - as described in the 12 methods discussed in this paper - can fuel innovation as illustrated in the Gendered Innovations case studies also discussed above.

Such research thrives on interdisciplinary work - with methods drawn from gender studies and from the technical fields involved. Such work requires shared conceptual frameworks and vocabularies. It also includes a willingness to meet partners half way. The Gendered Innovations project has hopefully developed methods that begin to facilitate this type of interdisciplinary, global research. 
Sex and gender analysis adds value to research and engineering by ensuring excellence and quality in outcomes and enhancing sustainability. Sex and gender analysis adds value to society by making research more responsive to social needs, and it adds value to business by developing new ideas, patents, and technology. The goal is to stimulate gender-responsible science and technology, thereby enhancing the quality of life for both women and men worldwide. Can we afford to ignore such opportunities?

\section{Additional file}

Additional file 1: Multilingual abstracts in the five official working languages of the United Nations and Portuguese.

Competing interests

The author declares that she has no competing interests.

Received: 15 April 2014 Accepted: 31 July 2014

Published online: 07 November 2014

\section{References}

Bairey Merz C, Mark S, Boyan B, Jacoba A, Shah P, Shaw L, Taylor D, Marbán E (2010) Proceedings from the scientific symposium: sex differences in cardiovascular disease and implications for therapies. J Womens Health 19(6):1059-1072 Beery A, Zucker I (2011) Sex bias in neuroscience and biomedical research. Neurosci Biobehav Rev 35(3):565-572 Bugiardini R, Bairey Merz C (2005) Angina with "normal" coronary arteries: a changing philosophy. JAMA 293(4):477-484 Bührer S, Schraudner M (2006) Wie Können Gender-Aspekte in Forschungs-vorhaben erkannt und bewertet werden? Fraunhofer Verlag, Karlsruhe

Burge R, Dawson-Hughes B, Solomon D, Wong J, King A, Tosteson A (2007) Incidence and economic burden of osteoporosis-related fractures in the United States, 2005-2025. J Bone Miner Res 22(3):465-475

Canadian Institutes of Health Research (CIHR) (2012) Gender, sex and health research guide: a tool for CIHR applicants. Enacted December 2010. http://www.cihr-irsc.gc.ca/e/32019.htm

Centers for Disease Control and Prevention (2002) National Health and Nutrition Examination Survey (NHANES): osteoporosis. United States Department of Health and Human Services National Center for Health Statistics, Washington, D.C

Clayton J, Collins F (2014) NIH to balance sex in cell and animal studies. Nature 509:282-283

European Commission (2003) European Commission Deputy-General for Research, Technology, and Development vademecum. Enacted March. ftp://ftp.cordis.europa.eu/pub/science-society/docs/gendervademecum.pdf

European Commission (2011) Proposal for a regulation of the European Parliament and of the council: establishing Horizon 2020, the framework programme for research and innovation, 2014-2020, article 15. European Commission, Brussels

European Commission (2013) Fact sheet: gender equality in Horizon 2020. European Commission, Brussels, Dec. 9

European Commission (2014) Vademecum on gender equality in Horizon 2020. RTD-B7 Science with and for Society, Brussels

Faulkner W (2001) The technology question in feminism: a view from feminist technology studies. Wom Stud Int Forum 24(1):79-95

Fausto-Sterling A (2005) The bare bones of sex, part 1: sex and gender. Signs: J Wom Cult Soc 30(2):1491-1527

Fausto-Sterling A (2008) The bare bones of race. Soc Stud Sci 38:657-694

Gates Foundation (2008) Bill and Melinda Gates Foundation gender impact strategy. Enacted June 2008. https://docs. gatesfoundation.org/Documents/gender-impact-strategy.pdf

Gates Foundation (2013) Agricultural development: creating gender-responsive agricultural development programs. http://genderedinnovations.stanford.edu/Creating-Gender-Responsive-Agricultural-Development-Programs.pdf

Gould K (1999) Coronary artery stenosis and reversing atherosclerosis. Oxford University Press, Oxford

Haafkens J, Klinge I (2007) Promoting attention to the gender dimension in health research: experiences from three centers of excellence in the EU. Universiteit Maastricht: Centre for Gender and Diversity \& Care and Public Health Research Institute

Haraway D (1988) Situated knowledges: the science question in feminism and the privilege of partial perspectives. Feminist Stud 14:575-599

Harding S (1991) Whose science? Whose knowledge. Cornell University Press, Ithaca

Harding S (2004) The feminist standpoint theory reader: intellectual and political controversies. Routledge, New York

Institute of Medicine, Board on Population Health and Public Health Practice (2012) Sex-specific reporting of scientific research: a workshop summary. National Academies Press, Washington D.C

Irish Research Council (2013a) Research project grants schemes, terms and conditions (search doc for "gender"). http:// genderedinnovations.stanford.edu/IRC_RPG_2013_TermsConditions_FINAL_2.pdf

Irish Research Council (2013b) Research project grants schemes, application form (search doc for "gender"). http:// genderedinnovations.stanford.edu/IRC_RPG_2013_Application_Form_FINAL.pdf

Johnson J, Sharman Z, Vissandjée B, Stewart D (2014) Does a change in health research funding policy related to the integration of sex and gender have an impact? PLoS One 9(6):e99900 
Kaczmarek I, Meiser B, Beiras-Frenandez A, Guethoff S, Überfuhr P, Angele M, Seeland U, Hagl C, Reichart B, Eifert S (2013) Gender does matter: gender-specific outcome analysis of 67,855 heart transplants. Thorac Cardiovasc Surg 61(1):29-36

Keller E (1985) Reflections on gender and science. Yale University Press, New Haven, 1985

Klinge I (2008) GenderBasic: promoting integration of the gender dimension in biomedical and health-related research. Centre for Gender and Diversity, School for Public Health and Primary Care, Maastricht

Lee K, Liao K, Ryu S (2007) Children's responses to computer-synthesized speech in educational media: gender consistency and gender similarity effects. Hum Commun Res 33(3):310-329

Leopold S, Beadling L, Dobbs M, Gebhardt M, Lotke P, Manner P, Rimnac C, Wongworawat M (2014) Fairness to all: gender and sex in scientific reporting. Clin Orthop Relat Res 472:391-392

Mack N, Grey T, Amsterdam A, Williamson N, Matta C (2010) Introducing female condoms to female sex workers in Central America. Int Perspect Sex Reprod Health 36(3):149-156

Marchetti M, Raudma T (eds) (2010) Stocktaking: 10 years of "Women in Science" policy by the European Commission, 1999-2009. Publications Office of the European Union, Luxembourg

Matson C, Murphy M, Sarver A, Griswold M, Bardwell V, Zarkower D (2011) DMTR1 prevents female reprogramming in the postnatal mammalian testis. Nature 476(7358):101-105

Miller V (2012) In pursuit of scientific excellence: sex matters. Am J Physiol Heart Circ Physiol 302:H1171-H1172

Nass C, Brave S (2005) Wired for speech: how voice activates and advances the human-computer relationship. MIT Press, Cambridge

Oertelt-Prigione S, Regitz-Zagrosek V (eds) (2012) Sex and gender aspects in clinical medicine. Springer Verlag, London Regitz-Zagrosek V (2012) Sex and gender differences in health. Eur Mol Biol Org Rep 13(7):596-603

Research Council of Norway (2014) Gender balance and gender perspectives in research and innovation: policy for the research council of Norway, 2013-2017. http://genderedinnovations.stanford.edu/Norway2014Policy.pdf

Richardson S (2013) Sex itself: the search for male and female in the human genome. The University of Chicago Press, Chicago

Robinson J, Wallace R, Limacher M, Ren H, Cochrane B, Wassertheil-Smoller S, Ockene J, Blanchette P, Ko M (2008) Cardiovascular risk in women with non-specific chest pain (from the Women's Health Initiative Hormone Trials). Am J Cardiol 102(6):693-699

Rosser S (2008) Building two-way streets to implement policies that work for gender and science. In: Schiebinger L (ed) Gendered innovations in science and engineering. Stanford University Press, Stanford, pp 182-197

Schiebinger L (ed) (2008) Gendered innovations in science and engineering. Stanford University Press, Stanford

Schiebinger $L$ (ed) (2014) Women and gender in science and technology, 4 vols. Routledge, London

Schiebinger L, Klinge I (2013) Gendered innovations: how gender analysis contributes to research. Publications Office of the European Union, Luxembourg

Schiebinger L, Schraudner M (2011) Interdisciplinary approaches to achieving gendered innovations in science, medicine, and engineering. Interdiscipl Sci Rev 36(2):154-167

Schiebinger L, Klinge I, Sánchezde Madariaga I, Schraudner M, Stefanick M (eds) (2011-2014) Gendered Innovations in Science, Health \& Medicine, Engineering, and Environment., http://genderedinnovations.stanford.edu/

Schraudner M (2010) Gender and innovation: Fraunhofer's discover gender research findings. In: Spitzley A, Ohlhausen P, Spath D (eds) The innovation potential of diversity, 169-182. Fraunhofer Verlag, Karlsruhe

Sekido R, Lovell-Badge R (2009) Sex determination and SRY: down to a wink and a nudge? Trends Genet 25(1):19-29

Sørensen K, Rommes E, Faulkner W (eds) (2012) Technologies of inclusion: gender in the information society. Tapir Academic Press, Trondheim

Szeri A (2009) Email communication with Schiebinger, L. (09/04/09)

Szeri A, Park S, Verguet S, Weiss A, Katz D (2008) A model of transluminal flow of anti-HIV microbicide vehicle: combined elastic squeezing and gravitational sliding. Phys Fluids 20(8):083101-083111

Szulc P, Kaufman J, Orwoll E (2012) Osteoporosis in men. J Osteoporos 2012:1-5

Taylor K, Vallejo-Giraldo C, Schaible N, Zakeri R, Miller V (2011) Reporting of sex as a variable in cardiovascular studies using cultured cells. Biol Sex Differ 2(11):1-7

Twenge JM, Campbell W, Gentile B (2012) Male and female pronoun use in U.S. Books reflects women's status, 19002008. Sex Roles 67(9-10):488-493

Uhlenhaut N, Jakob S, Anlag K, Eisenberger T, Sekido R, Kress J, Treier A, Klugmann C, Klasen C, Holter N, Riethmacher D, Schütz G, Cooney A, Lovell-Badge R, Treier M (2009) Somatic sex reprogramming of adult ovaries to testes by FOXL2 ablation. Cell 139(6):1130-1142

United Nations AIDS (2010) Report on the global AIDS epidemic. Joint United Nations Programme on HIV/AIDS, New York

Veitia R (2010) FOXL2 versus SOX9: a lifelong "battle of the sexes.". Bioessays 32(5):375-380

Wajcman J (2007) From women and technology to gendered technoscience. Inform Comm Soc 10(3):287-298

Wizemann T, Pardue M (eds) (2001) Exploring the biological contributions to human health: does sex matter? National Academies Press, Washington, D.C 